\title{
PARÓDIA, MEMÓRIA E SUJEITO POLÍTICO NO CONTO “MEMORIAS DE LA TIERRA", DE REINALDO ARENAS
}

\author{
- CHAYENNE ORRU MUBARACK
}

\section{RESUMO}

Este artigo analisa o conto "Memorias de la Tierra", do escritor cubano Reinaldo Arenas, a partir de uma perspectiva emancipadora, conforme proposta por Jacques Rancière em seu livro O desentendimento (RANCIÈRE, 1996). Verifica-se a emergência de um sujeito político no conto, composto pela voz do desacordo dos que eram considerados como a escória da sociedade cubana revolucionária em decorrência de sua homossexualidade. Tal subjetivação se dá por meio do uso da paródia (HUTCHEON, 1985) e pelo exercício da crítica da memória (RICHARD, 2010).

Palavras-chave: literatura caribenha, exílio cubano, sujeito político, Reinaldo Arenas

\section{ABSTRACT}

This article analyses the short story "Memorias de la Tierra", by the Cuban writer Reinaldo Arenas, from an emancipatory perspective, as it was proposed by Jacques Rancière in his book O desentendimento (RANCIÈRE, 1996). The story presents the emergence of a political subject, composed by the voice of the disagreement from those considered the scum of the revolutionary Cuban society due to their homosexuality. Such subjectification occurs with the use of parody (HUTCHEON, 1985) and the exercise of a memory's criticism (RICHARD, 2010).

Keywords: Caribbean literature, Cuban exile, political subject, Reinaldo Arenas 


\section{REINALDO ARENAS E A GERAÇÃO MARIEL}

A obra do escritor cubano Reinaldo Arenas é indissociável do que se chamou geração Mariel ${ }^{1}$. Para explicar o surgimento desta e, consequentemente, situar a leitura que proporemos para o conto"Memorias de la Tierra", publicado no livro Adiós a mamá, do escritor mencionado, deve-se tratar de dois problemas existentes durante o governo revolucionário socialista cubano: a homofobia e a censura. A crença de que os homossexuais eram pessoas doentes que precisavam ser tratadas e curadas sempre existiu na sociedade cubana, mesmo antes da Revolução. Entretanto, neste período, tal crença foi formalizada e institucionalizada pelo governo revolucionário. Este fenômeno é explicado por Pedro Marqués de Armas:

No pocos artículos publicados antes de la Revolución tratan del homosexual como individuo enfermo. [...] Sin embargo, solo después del 1959 se radicaliza la homofobia. La noción de individuo peligroso, que en Cuba tenía una larga historia, se amplió como nunca antes. A los efectos del biopoder y de las técnicas disciplinarias se suman ahora los de una política de Estado que se apodera de todo el cuerpo social. En estas condiciones, la alianza entre los dispositivos médicos y jurídicos fue asegurada a través de ciertas maniobras: se la coloca al servicio de las viejas leyes acopladas a preceptos socialistas, así como de nuevas leyes de carácter arbitrario. Y lo mismo ocurre a niveles normativos, mediante la vigilancia directa de escuelas e internados, y la orquestación de campañas de opinión hasta llegar, por último, a las purgas en la Universidad y en varias instituciones culturales (las llamadas "depuraciones") y a la reclusión forzosa de miles de homosexuales en las Unidades Militares de Ayuda a la Producción (UMAP). (ARMAS, 2014, pp. 181-182).

Grande parte desses valores homofóbicos se manifestavam em discursos, ensaios e congressos nos quais se disseminava o conceito de que a Revolução deveria fazer nascer o "hombre nuevo". Isso é desenvolvido no ensaio El socialismo y El hombre en Cuba, escrito por Che Guevara em 1965. Ele explicita que, por meio da educação e do trabalho, as massas atingiriam o nível de maturidade de seus governantes e seguiriam fazendo a revolução junto a eles. Nesta descrição de novo homem, Che Guevara incluía os que seguiam tal ideologia e desconsiderava os demais, referindo-se a eles como quem tem a tendência "a caminhar aislados" (GUEVARA, 2007, p. 16), a "mala hierba" (GUEVARA, 2007, p. 25) e, fazendo referência a alguns intelectuais, escreveu que "la culpabilidad
[1] A denominação "geração de Mariel” foi proposta por Jesús J. Barquet no texto "La generacióndel Mariel”, integrante do dossiê de textos em homenagem ao êxodo de Mariel no número 08 da Revista Encuentro. $\mathrm{O}$ autor descreve que "En términos estrictamente literarios, la propia denominación de "generación del Mariel" resulta problemática y dudosa para muchos, por cuanto no responde a factores propiamente intraliterarios sino más bien a factores extraliterarios. En lo intraliterario, no creo posible detectar ninguna orientación estilística que sea común a todos: Ios caracteriza "la diferenciación", afirma Valero (“La generación” 14). Si bien en el terreno semántico son detectables las huellas, más o menos evidentes, de un abordaje crítico a veces altisonante y abertamiente antioficialista de la realidad cubana posterior a 1959 (abordaje que hacía a muchos de estos autores impublicables dentro de la Isla), las formas literarias escogidas por cada autor para expresar ese descontento e irreverencia ante cualquier autoridad se caracterizan por su eclecticismo y carácter antiprogramático. Coinciden, pues, en aspectos tales como el tono de angustia y furia (Abreu, "Art") y las imágenes de libertad y opresión (Bertot) que aparecen recurrentemente en sus textos". 
de muchos de nuestros intelectuales y artistas reside en su pecado original: no son autenticamente revolucionarios" (GUEVARA, 2007, p. 26).

Em 1971, ocorreu o Primer Congreso Nacional de Educación y Cultura, em que se estabeleceram alguns parâmetros que regeriam as políticas culturais e educacionais a partir de então. Na seção "sobre la sexualidad", há algumas decisões sobre a homossexualidade:

Respecto a las desviaciones homosexuales se definió su carácter de patología social. [...] En el tratamiento del aspecto del homosexualismo la Comisión llegó a la conclusión de que no es permisible que por medio de la "calidad artística" reconocidos homosexuales ganen influencia que incida en la formación de nuestra juventud. [...] Finalmente, se acordó solicitar penas severas para casos de corruptores de menores, depravados reincidentes y elementos antisociales irreductibles. (GUEVARA, 2007, p. 13).

O governo exigia uma aliança entre as produções intelectuais e a ideologia revolucionária. A UNEAC (Unión de Escritores y Artistas de Cuba) foi o órgão estatal criado para estimular vínculos das obras com a Revolução. Tal órgão possuía os direitos autorais sobre as publicações dos escritores cubanos, que tampouco podiam publicar fora da ilha.

Nos anos 1970, quando se realizou o congresso do qual citamos os excertos, houve um endurecimento das políticas culturais da ilha. Exigia-se que os homens fossem viris e produtivos, contribuindo durante o processo revolucionário, e criou-se a concepção de que os homens gays eram improdutivos e, portanto, inúteis para a Revolução, tendo que ser curados de sua "doença". Escrever também era uma atividade improdutiva se os escritos não estivessem de acordo com a ideologia revolucionária e não fossem utilizados na educação dos jovens. A única função intelectual adequada era a educação das novas gerações junto ao governo.

O caso Padilla, como veio a ser conhecido posteriormente, foi o primeiro episódio que resultou em um desencanto da intelectualidade internacional com a política cultural adotada pela Revolução. Em 1968, Heberto Padilla (19322000) publicou o livro de poemas Fuera de juego. A primeira recepção do livro pela UNEAC foi positiva. Entretanto, em 1971, algumas críticas à Revolução contidas no livro resultaram na prisão do autor. Algum tempo depois, o escritor foi obrigado a fazer uma declaração pública à UNEAC, uma espécie de mea culpa, retratando-se e retirando suas críticas ao governo. Como consequência, alguns renomados intelectuais como Octavio Paz (1914-1998), Julio Cortázar (1914-1984), Jean Paul Sartre (1905-1980) e Simone de Beauvoir (1908-1986) elaboraram e assinaram uma carta endereçada ao governo cubano, pedindo ex- 
plicações em relação ao ocorrido. Devido a tais pressões internacionais, Heberto Padilla foi liberado, deixou a ilha em 1980 e se exilou nos Estados Unidos. Em decorrência destes problemas, um grande número de escritores e intelectuais se exilaram de Cuba.

A geração Mariel possui um marco histórico fundacional situado em $1^{\circ}$ de abril de 1980, quando seis cidadãos cubanos invadiram a embaixada do Peru para pedir asilo político. O governo revolucionário pediu que a embaixada lhes entregasse os invasores, o que não ocorreu. Como resposta, o governo declarou, em 4 de abril de 1980, que a partir daquele momento a embaixada seria responsável pelo que ocorresse lá dentro e retirou a guarda oficial. O resultado foi a tomada do local, no intervalo de dois dias, por mais de 10 mil cubanos pedindo asilo político. Em 6 de abril, o governo retomou a guarda da embaixada.

Sob pressão internacional, o governo de Fidel Castro decidiu ceder e abrir o porto de Mariel para que os dissidentes cubanos de Miami pudessem levar para lá suas famílias e compatriotas dissidentes. É importante lembrar que, em 1960, houve uma primeira onda migratória de cubanos contrarrevolucionários para Miami, criando uma comunidade naquele território. Em 1980, cerca de 125 mil cubanos saíram de Cuba pelo porto de Mariel. Isso colocou o governo norte-americano de Carter em uma crise internacional e desestabilizou a comunidade cubana em Miami, que tampouco desejava uma migração em massa. Os cubanos que lá desembarcavam recebiam o apelido pejorativo de marielitos, efeito do nome do porto por onde haviam emigrado. Eles eram vistos como escória da sociedade cubana, posto que o discurso oficial depreciava moral, social e intelectualmente os que saíam da ilha, criando um estigma para depreciar o caráter daqueles que rompiam com a revolução. Essa geração se autonomeou geração de Mariel e era constituída por esses indivíduos duplamente indesejados tanto em Miami, quanto em Cuba (MARQUES, 2008, pp. 478-487).

Entre os que saíram de Cuba por Mariel estava o escritor Reinaldo Arenas (1943-1990). Apesar de haver recebido uma menção de honra no concurso literário da Casa de las Américas, importante instituição literária latino-americana, por seu primeiro romance, Celestino antes del alba, em 1967, Arenas teve problemas com o governo cubano quando publicou seu segundo romance, El mundo alucinante, na França, sem autorização da UNEAC. A partir deste episódio, seguiram-se outros de represália não só pelo conteúdo de sua obra como também por sua homossexualidade. $O$ escritor foi preso e conseguiu liberdade com o auxílio da pressão de contatos internacionais após cumprir dois dos oito anos aos quais fora condenado. Conseguiu sair pelo porto de Mariel e estabeleceu-se inicialmente em Miami, onde fundou a revista literária Mariel. Posteriormente, mudou-se para Nova York. 


\section{MEMORIAS DE LA TIERRA}

O conto do qual trataremos a seguir, "Memorias de la Tierra”, foi publicado no livro Adiós a mamá. A escolha específica deve-se ao fato de que ele condensa características relevantes para pensar a obra de Reinaldo Arenas. Debruçar-nos-emos sobre três delas: o uso da paródia, a subjetivação de indivíduos litigiosos e o exercício da crítica da memória.

"Memorias de la Tierra" é dividido em quatro partes. A primeira, "Monstruo I", conta a história de uma cidade governada por um monstro, que era elogiado e amado pelos que lá viviam. Um dia, um cidadão começa a depreciá-lo e é rechaçado pelos demais habitantes. A segunda parte, "Los negros", trata da sacralização dos brancos como tradição constituinte da cidade. Assim, os negros que lá viviam começaram a ser perseguidos e exterminados. Alguns deles, que ocupavam cargos oficiais no governo do monstro, fingiam ser brancos para alcançarem tais cargos. Para realizar o extermínio, a "Gran República-Monolítica-Universal-Libre", um dos apostos desta cidade, comprava armas da "Séptima Galaxia", que havia enfrentado o território na "Quinta Guerra Supertérmica", conflito anterior à consolidação da "Gran República". Essa parte é finalizada com o informe de um dos perseguidores dos negros a respeito da aniquilação de todos os indesejados daquela República. Em seguida, o monstro mata o informante (que também era um dos assassinos de negros) e o sangue que jorra dele mostra-se negro, evidenciando a dissimulação da personagem. A seguir está a parte três, "La mesa", em que se narra a fome em que viviam os habitantes da cidade até encontrarem uma mesa cheia de comida e com um enxame de moscas. Esta parte termina com os habitantes da cidade se alimentando fartamente com tudo que estava em tal mesa. A quarta e última parte, "Monstruo II", narra o momento em que os habitantes perceberam que o monstro era de fato um monstro, mas ninguém conseguia identificar em que parte ele se encontrava. A "Comisión de Salvamento Universal" enviou, então, uma nave para a cidade e o detectou. $O$ narrador conta que os habitantes precisavam sair do território com a ajuda de tal nave. Entretanto, após a identificação do monstro, os tripulantes da nave da Comisión apenas regressaram para onde pertenciam.

A trama do conto é uma paródia da história da Revolução Cubana. Mobilizamos o conceito de paródia tal como o desenvolveu a pesquisadora canadense Linda Hutcheon, para quem este recurso textual ultrapassa a carnavalização e o humor aos quais normalmente é associada. Além disso, pode ser utilizada como instrumento dessacralizador de discursos. No livro Uma teoria da paródia, a autora escreve que

A paródia é, pois, na sua irônica "transcontextualização"e inversão, repetição com diferença. Está implícita uma distanciação 
crítica entre o texto em fundo a ser parodiado e a nova obra que incorpora, distância que pode ser apenas bem-humorada, como pode ser depreciativa; tanto pode ser criticamente construtiva, como pode ser destrutiva. (HUTCHEON, 1985, p. 48)

[...] a paródia é, pois, repetição, mas repetição que inclui diferença (Deleuze 1968); é imitação com distância crítica, cuja ironia pode beneficiar ou prejudicar ao mesmo tempo. Versões irônicas de "transcontextualização"e inversão são seus principais operadores formais, e o âmbito de ethos pragmático vai do ridículo desdenhoso à homenagem reverencial. (HUTCHEON, 1985, p. 54)

A mesma autora, no texto "La política de la parodia postmoderna", escreve: "la parodia postmodernista es una forma problematizadora de los valores, desnaturalizadora, de reconocer la historia (y mediante la ironía, la política) de las representaciones" (HUTCHEON, 1993, p. 188). O caráter paródico da obra de Reinaldo Arenas foi estudado por críticos como Eduardo C. Béjar em La textualidad de Reinaldo Arenas: juegos de la escritura posmoderna. De acordo com a resenha da obra de Béjar, realizada por Fernando Burgos:

La tesis central de Béjar sostiene que la escritura de Reinaldo Arenas no tiene correspondencia con la sistematicidad de una modelación estética determinada, es más bien una compenetración simultánea en una diversidad de discursos, y al mismo tiempo una evasión de todos ellos. Escritura de desmantelaciones, de sorpresas, de juegos, de trampas; dispuesta a hacerse barroca para luego liberarse de los excesos o llana a simplificarse para estallar en significaciones y en simbologías rebeldes a traducciones y a desciframientos unívocos. En ambos casos, hay una actitud que elude lo programático y lo institucional, que busca siempre la vertiente de las marginalidades. La realidad es la Historia, pero ésta no es el recorrido de acontecimientos sino una marca extraña en el individuo. La historia no está percibida como una progresividad recuperadora de las potencialidades del individuo, sino como una totalización pesadillesca. Frente a la capacidad anulante de esa historia, la respuesta es la invención de su parodia junto a una búsqueda de conocimiento a través de lo alucinante, solo que el conocimiento no es una medida del saber, sino una penetración en los procesos de la imaginación. (BURGOS, 1989, p. 329).

Burgos apresenta o argumento de Béjar sobre a retomada da realidade histórica como fonte das paródias alucinantes de Reinaldo Arenas. A trama do 
conto "Memorias de la Tierra" pode ser lida como um texto de ficção científica, mas este consiste em uma paródia do discurso histórico oficial.

Em "Monstruo I", parodiam-se os momentos iniciais da Revolução Cubana, em que Fidel Castro emerge como líder do processo e consegue grande adesão popular. O narrador em terceira pessoa utiliza a metatextualidade. $O$ conto inicia com: "En aquella ciudad también había un monstruo. Era una combinación de arterias que suspiraban, de tráqueas que oscilaban como émbolos furiosos, de pelos encabritados y vastos, de cavernas cambiantes y de inmensas garrafas que se comunicaban directamente con las orejas siniestras" (ARENAS, 2006, p. 260). Cinco parágrafos adiante, quando o narrador conta sobre alguém que começara a difamar o monstro, temos: "El que hablaba pronunciaba un discurso ofensivo que comenzaba, más o menos, de esta forma: "En aquella ciudad también había un monstruo. Era una combinación de arterias que supuraban, de tráqueas que oscilaban como émbolos furiosos..." (ARENAS, 2006, p. 261). Embora a narração do conto seja em terceira pessoa, com um narrador omnisciente, temos a coincidência entre os enunciados do narrador e do personagem que maldizia o monstro, o que possibilita uma leitura do conto como se o narrador observador fosse um dos personagens. Após essa metatextualidade, a narração passa a ser feita em primeira pessoa.

Em "Los negros", parodia-se o momento histórico em que Fidel Castro anuncia à população cubana que a Revolução foi comunista. A “Gran República-Monolítica-Universal-Libre" é o nome que o autor utiliza no texto para referir-se a Cuba. Esta denominação é paradoxal, pois "monolítica" é um adjetivo que significa "rígido, inflexível", ao passo que "universal" e "libre" supõem maleabilidade e flexibilidade. $\mathrm{O}$ epíteto significa que a república era simultaneamente rígida e flexível, o que além de paradoxal é irônico, já que, em seguida narra-se a perseguição de uma categoria de pessoas, demonstrando que a liberdade e a universalidade implicadas no nome eram válidas apenas para grupos que se encaixassem nos padrões que a república comandada pelo monstro aceitava. No caso da segunda parte do conto, o grupo fora dos padrões e que, por isso, sofria perseguição oficial, era o composto por "los negros", referência aos homossexuais. O narrador coloca em jogo uma dupla moral ao narrar um “hecho curioso", que consiste no caso do perseguidor de negros que fingia ser branco, mas, ao morrer, tem a cor negra de sua pele testemunhada por todos. A paródia supõe que fingir-se heterossexual foi uma consequência do intenso combate à homossexualidade realizado durante a Revolução.

A terceira parte, "La mesa", é uma paródia da vida dentro de Cuba durante o governo de Fidel Castro. O governo estadunidense adotou uma política de embargo econômico em relação à ilha. Durante alguns anos, também houve racionamento de mantimentos e de objetos em geral, além da estatização de bens. No conto, narra-se um momento em que os habitantes da cidade encon- 
tram uma mesa cheia de alimentos aos quais não tinham acesso:

Así persistíamos con nuestras jabas y botellas, platos y cucharas; todo guardado y defendido a riesgo de nuestra vida. Así persistíamos, fijos en la inmensa fila que desembocaba ante aquella mesa vacía... El enemigo, desde luego, hacía todos los esfuerzos por dispersarnos; nosotros, todos los esfuerzos para aniquilarnos.

Pero cuando los dos que el azar reunía llegábamos a la mesa y nos sentábamos, ya de espaldas a la muchedumbre desplegábamos nuestras comidas y bebidas (conservadas gracias a meses de abstinencias) y empezábamos a mirarnos sin dejar de reír. (ARENAS, 2006, p. 265)

O excerto contém não só uma paródia do racionamento mencionado, mas também da insegurança dos habitantes da ilha uns com os outros. Não se sabia quem trabalhava para o governo como espião à paisana e, portanto, poderia delatar conhecidos caso detectasse um comportamento antirrevolucionário (a homossexualidade entre eles). O narrador descreve isso na última frase do primeiro parágrafo transcrito acima. O mote da dupla moral reaparece em uma situação distinta. Anteriormente, tratou-se dela em relação a indivíduos antirrevolucionários que faziam parte do regime ou fingiam ser algo diferente do que eram somente para sobreviver. Aqui, deparamo-nos com a dupla moral de membros que trabalhavam para o regime castrista.

A última parte de "Memorias de la Tierra", denominada "Monstruo II", parodia momentos em que, apesar de haver uma política externa de diversos países contrária a alguns acontecimentos ocorridos ao longo do Governo Revolucionário, esses países não ajudavam efetivamente a população cubana. Um exemplo são as políticas estadunidenses para lidar com o enorme número de exilados cubanos que partiam para Miami pelo porto de Mariel. Segundo Leandro Rickley Marques e Isabel Ibarra Cabrera, depois que o governo cubano abriu o porto de Mariel para saída de dissidentes do regime:

[...] o governo dos Estados Unidos da América, ao perceber que teria que receber uma imigração massiva, tentou impedi-la. Segundo a legislação norte-americana vigente na época, todo cidadão cubano que tocasse o solo dos EUA poderia pedir o visto permanente [...]. O protecionismo aos dissidentes cubanos devia-se exclusivamente à Guerra Fria e à certeza de que poucos conseguiriam chegar aos Estados Unidos da América devido às restrições impostas por Cuba à emigração. Até então, todo 
cubano que conseguia chegar à Flórida era saudado como um herói que chegava ao paraíso vindo do inferno; dava entrevista nos canais de comunicação americanos e era logo amparado por várias instituições. [...] o governo norte-americano tentou impedir o desembarque dos dissidentes que chegavam pelo porto de Mariel desde o início, mas isso não foi possível devido à legislação favorável à imigração cubana e à cobertura internacional. O presidente norte-americano Jimmy Carter inclusive declarou no dia 6 de maio de 1980 estado de emergência em toda a Flórida, e a Casa Branca denunciou no dia 7 de junho que o governo cubano tinha exportado criminosos comuns retirados das prisões e enviados diretamente aos Estados Unidos da América. Esse tipo de manobra evidentemente contribuiu para a marginalização de todos os que saíram pelo porto de Mariel. Contudo, o governo norte-americano não teve outra opção senão receber os exilados [...]. Após os episódios do Mariel, qualquer cubano que pretendesse entrar na América passou a precisar obter, antes, um visto de entrada na embaixada dos Estados Unidos em seu passaporte. Isso, evidentemente, não era tarefa das mais fáceis [...]. (CABRERA, MARQUES, 2013)

O trecho expõe o interesse inicial do governo Carter em receber os cubanos exilados como se fossem heróis que escapavam de Cuba. Isto se transformou em um problema quando o governo de Fidel Castro abriu o porto de Mariel para a saída de dissidentes e o fluxo de exilados aumentou exponencialmente. Dificultou-se o acesso ao visto de imigração e, com o estado de alerta decretado por Carter, os marielitos foram ainda mais marginalizados pelos estadunidenses, sendo vistos como escória social. Ainda nesta parte, o narrador relata a ajuda da "Comisión de Salvamento Universal" na identificação do monstro e, posteriormente, o abandono dessa comissão em relação aos habitantes do território. Essa comissão parodia os Estados Unidos, que inicialmente receberam os cubanos como heróis, auxiliando-os devido a interesses em criar imagens que injuriassem Cuba durante a Guerra Fria. Posteriormente, os habitantes exilados foram marginalizados e desamparados. No conto, temos:

El monstruo, finalmente, había sido detectado.

Ahora, despejado el enigma, sólo se trataba de salir huyendo. Elevarse cada vez más y volar por el infinito (la nave era un sitio seguro) atravesando luminarias y constelaciones: la inmensa noche deshabitada, no por centelleante menos noche.

Pero, tácitamente, todos acudieron a la sala de controles. Mani- 
pularon los mecanismos $y$, descendiendo, regresaron. (ARENAS, 2006, pp. 268-269).

O conto parodia, portanto, distintos momentos do discurso histórico oficial. Esse tipo de paródia pode ser interpretado como um exercício de crítica da memória, categoria proposta por Nelly Richard. A memória é um terreno de disputa. Por um lado, há a memória oficial, que tenta apaziguar os conflitos ocorridos em determinado momento histórico e oferecer uma versão dos acontecimentos que privilegie o conceito de nação. Do outro lado, está a "crítica de la memoria", que nega o dispositivo da memória oficial e quer manter vivo o passado discordante e as distintas leituras da história. Sobre isso, Nelly Richard escreve:

La memoria designa una zona de asociaciones voluntarias e involuntarias que se mueve entre el pasado y el presente, ambos conocidos como formaciones incompletas en las que se entrelazan lo ya consumado con lo aún no realizado. Es porque el pasado es inconcluso que el trabajo residual de la memoria se mueve de escena en escena, a la búsqueda retrospectiva de aquellas intermitencias que aún contienen energías latentes. (RICHARD, 2010, p. 16, grifos da autora)

La"crítica de la memoria"realizada en este libro cursa un trayecto no sólo temporal sino que espacial, al desplazarse por distintos escenarios de actuación [...] que le dan cuerpo - materialidad sígnica - a un recuerdo de los años de la dictadura entretejido con el presente de su relectura que deambula libremente por diversos soportes y formatos de inscripción. (RICHARD, 2010, pp. 18-19).

O discurso dos meios oficiais castristas ocupa a posição de memória oficial, uma versão dos fatos que se quer privilegiar. Dessa forma, o conto de Reinaldo Arenas apresenta uma releitura dos mesmos fatos, "repetição com diferença" de acordo com Linda Hutcheon, apresentando parodicamente uma retrospecção de episódios que ainda contém energias latentes. A escritura do conto dá o que Richard chama de "materialidad sígnica" à essa crítica da memória.

A teoria de filosofia política desenvolvida pelo sociólogo francês Jacques Rancière em seu livro $O$ desentendimento possibilita a ampliação do espectro de leitura deste conto. De acordo com esse estudioso, a divisão do sensível se dá por meio de um dano inicial. Nas sociedades antigas, por exemplo, a divisão da sociedade não incluía a categoria dos plebeus, pois eles não eram considerados seres humanos, e sim animais que deveriam apenas seguir ordens. Entretanto, de acordo com Rancière, para seguir uma ordem é necessário ter duas habi- 
lidades: a de entender a ordem e a de entender que é necessário obedecê-la. Isso se dá porque os plebeus possuíam a habilidade da fala. Por meio dela, eles se tornavam iguais aos outros, porque também eram seres que não utilizavam os sons para expressarem apenas o bom e o ruim, mas também o útil e o justo. Sendo iguais às outras categorias pela habilidade da fala, deveriam estar incluídos na contagem da sociedade, o que não ocorria. Esse é o dano inicial, ou seja, uma divisão do sensível que exclui determinada parcela da sociedade. $O$ desentendimento reside no fato de uma mesma palavra ser compreendida de duas maneiras distintas por grupos sociais diferentes. No exemplo, o que os plebeus pronunciavam era recebido pelas classes sociais superiores como um som sem significação efetiva e pelos próprios plebeus como uma comunicação com produção de sentido. Tal dissenso gerou o dano.

O que chamamos normalmente de política, Rancière nomeia de polícia. Tudo que mantém a divisão do sensível como ela está pertence à ordem policial. Isso inclui as leis, a organização dos poderes e os sistemas de legitimação da distribuição dos lugares e funções. A política é definida como "a prática na qual a lógica do traço igualitário assume a forma do tratamento de um dano, onde ela se torna o argumento de um dano principal que bem ligou-se a tal litígio determinado na divisão das ocupações, funções e lugares" (RANCIÈRE, 1996, p. 47). Não existe um lugar para se fazer política e nem um agente habilitado a fazê-lo. Quando ocorre a reconfiguração do campo do sensível através da subjetivação de certo grupo social, ocorre política. Essa subjetivação é a capacidade de afastamento de certo grupo da ordem policial, processo que possibilita a visão de uma nova partilha do sensível que inclua os incontados, transformando-os em um grupo por traços comuns, ou seja, o grupo que constitui a parte dos sem parte. Por meio dessa subjetivação, emana um sujeito político e ocorre a política. Para que algo seja político é necessário, portanto, o encontro da lógica policial com a igualitária, o que nunca será preconstituído. O sujeito surge nesse momento, reconfigura o sensível e logo se dissolve, pois no momento em que certa classe não contada toma parte na contagem, ela passa a figurar em uma nova ordem policial.

A Revolução Cubana instaurou uma nova partilha do sensível. Através de métodos que pregavam ideologias configuradas pelo governo revolucionário, desejava-se formar um novo tipo de homem que estivesse em consonância com tais ideologias e com os valores revolucionários. O aparato estatal, ou ordem policial, era responsável pela manutenção da nova divisão do sensível instituída. Ele era composto por medidas como a fixação de tarefas para os cidadãos pelo governo, a máquina educacional do Estado, a aplicação de castigos aos que não se enquadravam nessa nova ordem, a necessidade de desenvolvimento de um mecanismo cultural que atuasse nesse âmbito da mesma forma que o aparelho estatal trabalhava no âmbito educacional. A exclusão dos que não 
estavam dentro da lógica vigorante era impreterível. Uma das categorias que não estava prevista por tais regras e deveria ser educada por meio do trabalho para se tornar o novo homem cubano era a dos homossexuais, como tratamos no item 1 ao citarmos alguns parâmetros para o comportamento da juventude elaborados durante o Primer Congreso Nacional de Educación y Cultura.

No conto escrito pelo marielito Reinaldo Arenas $^{2}$ há a inserção de sujeitos na partilha do sensível quando estes se apropriam das características pelas quais são excluídos da sociedade e passam a definir-se por meio delas enquanto sujeitos políticos. Em "Memorias de la Tierra", tal inserção se dá por meio da coincidência entre o narrador e o personagem dissidente e pela paródia de um discurso histórico. A concomitância de enunciados ("El que hablaba pronunciaba un discurso ofensivo que comenzaba, más o menos, de esta forma: "En aquella ciudad también había un monstruo. Era una combinación de arterias que supuraban, de tráqueas que oscilaban como émbolos furiosos...") $)^{3}$ insere o personagem que maldizia o monstro na partilha do sensível e, mais do que isso, quando o narrador identifica-se com ele, percebemos que ele lhe dá a voz, entrega-lhe a narração do texto.

Na trama, a subjetivação da população da cidade se dá no momento em que todos percebem a tirania do monstro e se unem para tentar deixar o território por ele governado. Cria-se um sujeito político. Todavia, isto não implica liberdade, uma vez que ela nunca esteve em jogo e o conto explicita a impossibilidade de sair da lógica monstruosa, pois ainda há o "Monstruo II": detecta-se o problema, mas não é possível solucioná-lo, eles não conseguem abandonar a localidade.

O recurso da paródia do discurso histórico possibilita, por outro lado, o exercício de crítica da memória, que expõe uma versão da história que contesta a oficial. Ao fazê-lo, o narrador privilegia um ponto de vista apartado pela oficialidade e, novamente, dá voz ao sujeito político que possui este ponto de vista, inserindo-o dentro da partilha do sensível.
[2] A possibilidade de adjetivá-lo dessa forma se deve, entre outros fatores, à saída de Cuba pelo porto de Mariel e à fundação da revista literária Mariel em Miami.O primeiro número de Mariel, Revista de Literatura y Arte, saiu em 1983, três anos depois do episódio do êxodo de Mariel. O conselho de direção da revista era composto pelos escritores Reinaldo Arenas, Juan Abreu e Reinaldo García Ramos. A revista era um espaço para publicação de artistas do exílio. $\mathrm{Na}$ última página do último número da revista, o conselho de editores escreve que "[...] ha quedado demostrado que se puede hacer una revista literaria y dinámica en el exilio. [...] Creemos que con esto hemos contribuido modestamente a modificar la errónea imagen que el castrismo quiso proyectar sobre los refugiados llegados a Estados Unidos durante el éxodo de Mariel" ("La última página" in: Mariel, Revista de literatura y arte. Número 08, 1985, p. 40).

[3] ARENAS, 2006, p. 26.
CHAYENNE ORRU MUBARACK - Mestranda pelo Programa de Pós-Graduação em Língua Espanhola e Literaturas Espanhola e Hispano-Americana do Departamento de Letras Modernas. Universidade de São Paulo, São Paulo, Brasil. Contato: chayenne.mubarack@usp.br 


\section{REFERÊNCIAS BIBLIOGRÁFICAS}

ARENAS, Reinaldo. Termina el desfile seguido de Adiós a mamá. Barcelona: Tusquets Editores, 2006.

ARMAS, Pedró Marqués de. Ciencia y poder en Cuba. Racismo, homofobia y nación (1790 - 1970). Madrid: Editorial Verbum, 2014.

BURGOS, Fernando. Reseña de Eduardo C. Béjar: "La textualidad de Reinaldo Arenas. Juegos de la escritura posmoderna". In: Revue Romane, 24/02/1989, p. 329. Disponível em < https://tidsskrift.dk/index.php/revue_romane/issue/ view/566 >. Acesso em 20/04/2016.

CABRERA, Isabel Ibarra; MARQUES, Rickley Leandro. "Migrações contemporâneas de cubanos: entre o Mariel (1980) e a crise de balseiros (1994). In: Anais do XXVII Simpósio Nacional de História. Disponível em <http://www. snh2013.anpuh.org/resources/anais/27/1364766811_ARQUIVO_anpuhnatal.pdf>. Acesso em 23/10/2016.

Declaración del Primer Congreso Nacional de Educación y Cultura. La Habana, 1971.

GUEVARA, Ernesto Che. El socialismo y el hombre en Cuba. La Habana: Ediciones Abril, 2007.

HUTCHEON, Linda. Uma teoria da paródia. Lisboa: Edições 70, 1985, p. 48. "La política de la parodia postmoderna". In: Criterios, edición especial de homenaje a Bajtín, julio 1993, p. 188.

Mariel, Revista de literatura y arte. Números 01 - 08. Disponível em < http:// revista-mariel.com/ >. Acesso em 30/11/2015.

MARQUES, Leando Rickley. "A crise da Embaixada do Peru." In: A Condición Mariel. Revista Brasileira do Caribe, vol. III, núm. 16, enero-junio, 2008, pp. 473 - 506. Disponível em < http://www.redalyc.org/articulo.oa?id=159114271011 >. Acesso em 26/01/2016.

RANCIĖRE, Jacques. O desentendimento. São Paulo: Editora 34, 1996. 
de 1998. Disponível em< http://www.cubaencuentro.com/var/cubaencuentro. com/storage/original/application/20a4f68744182837038d78fae421f96c.pdf >. Acesso em 24/10/2016.

RICHARD, Nelly. Crítica de la memoria. Santiago de Chile: Ediciones Universidad Diego Portales, 2010. 